\title{
Dermatoses Autoinfligidas 'Secretas': Um Desafio em Dermatologia
}

\section{'Secret' Self-Inflicted Skin Lesions: A Challenge in Dermatology}

\author{
Bárbara Roque FERREIRA $\varangle^{1}$, José Pedro REIS ${ }^{1}$, Américo FIGUEIREDO ${ }^{1}$ \\ Acta Med Port 2017 Feb;30(2):155-155 - http://dx.doi.org/10.20344/amp.7418
}

Palavras-chave: Comportamento Autodestrutivo; Doenças da Pele/psicologia; Pele/lesões

Keywords: Self-Injurious Behavior; Skin Diseases/psychology; Skin/injuries

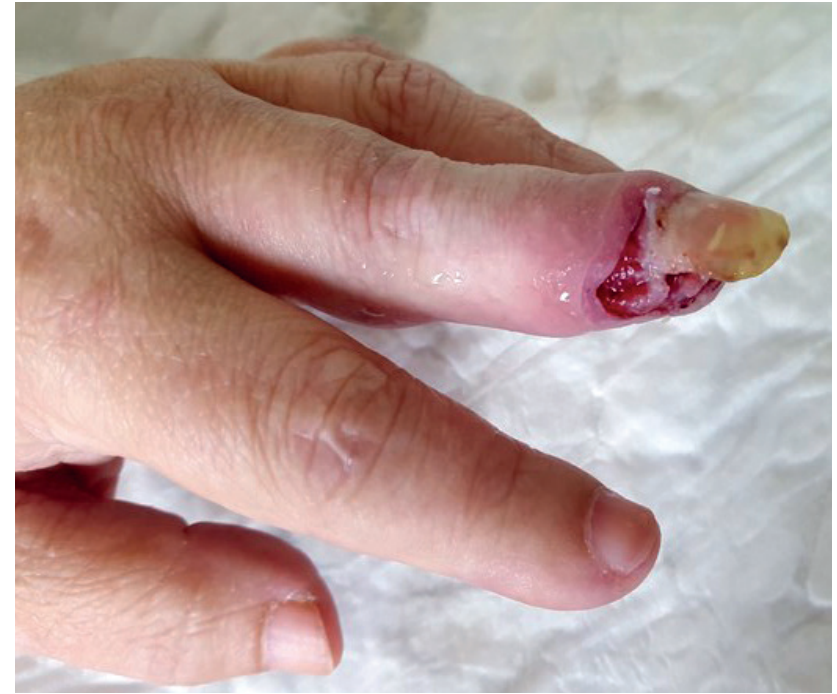

Figura 1 - Lesão ulcerada autoinfligida 'secreta' (negada pela doente), envolvendo o terceiro dedo da mão esquerda

Apresentamos uma doente com lesões erosivo-ulceradas, envolvendo diversas áreas corporais, sem predileção topográfica, com anos de evolução. Relatava início das lesões como pápulas, com dor intensa, evoluindo posteriormente para erosões e úlceras. Colocou-se a hipótese de pioderma gangrenoso, excluída após estudo complementar, nomeadamente, histopatologia de lesões ativas e outros exames laboratoriais negativos, inexistência de doenças sistémicas ligadas a essa hipótese clínica e ausência de resposta à corticoterapia sistémica. ${ }^{1} \mathrm{Na}$ avalia-

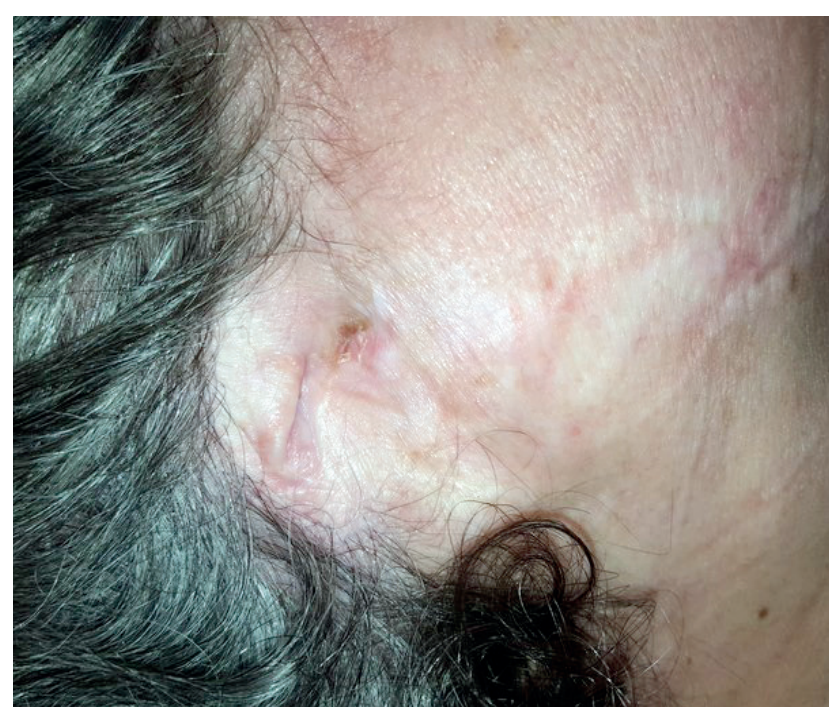

Figura 2 - Amputação autoinfligida do pavilhão auricular direito

ção mais recente, tem lesões em atividade no terceiro dedo da mão esquerda (Fig. 1), no abdómen e na região vulvar bem como várias lesões cicatriciais. O resultado da avaliação sugere síndrome de Münchausen, condicionando uma dermatose autoinfligida 'secreta'. Esta designação foi recentemente proposta pela Sociedade Europeia de Dermatologia e Psiquiatria para um grupo de lesões cutâneas autoinfligidas e negadas ou escondidas pelos doentes cuja terminologia não tem sido consensual. ${ }^{2}$ A Fig. 2 mostra a amputação autoinfligida do pavilhão auricular direito.

\section{REFERÊNCIAS}

1. Bolognia JL, Jorizzo JL, Schaffer JV. Dermatology. $3^{\text {rd }}$ ed. London: Elsevier; 2012.

2. Gieler U, Consoli SG, Tomás-Aragones L, Linder DM, Jemec GB, Poot F, et al. Self-inflicted lesions in dermatology: terminology and classification-a position paper from the European Society for Dermatology and Psychiatry (ESDaP). Acta Derm Venereol. 2013;93:4-12.

\footnotetext{
1. Serviço de Dermatologia e Venereologia. Centro Hospitalar e Universitário de Coimbra. Coimbra. Portugal.

$\square$ Autor correspondente: Barbara Roque Ferreira. barbara.roqueferreira@gmail.com

Recebido: 19 de janeiro de 2016 - Aceite: 01 de agosto de 2016 | Copyright @ Ordem dos Médicos 2017
} 